\title{
Analysis on the Human Settlement Environment of Huizhou Ancient Villages Based on the Heritage of Ancient Roads -- a Case Study of Chengkan Village
}

\author{
Bi Zhongsong ${ }^{1,2}$, Chen Chun ${ }^{2}$, Li Yunzhang ${ }^{2}$, and Cheng Peng ${ }^{1, *}$ \\ ${ }^{1 *}$ College of Architectural and Engineering \& Research Center of Huizhou Architecture, Huangshan University,245041 Huangshan, \\ China \\ ${ }^{2}$ College of Architecture and Environment, Sichuan University,610065 Chengdu, China
}

\begin{abstract}
The ancient road cultural route is an important part of Huizhou cultural heritage, which is closely related to Huizhou tradition. Huizhou ancient villages are important historical and cultural heritage. The important features of their locations and layouts are the high integration with nature, forming a traditional residential environment pattern of "backing mountain, surrounding water and facing screen". From the perspective of Huizhou Ancient Road, this paper selects Chengkan ancient village, which is an important cultural route of "Shuyuan Lingshan Chengkan ancient road", as the research object, and takes the construction of human settlements as the main research content. From the natural environment and cultural background, and the formed human environment as the starting point, the paper focuses on the village agglomeration spatial pattern, the village water system, the street space environment, the architectural environment and the Shuikou landscape environment to analyze the characteristics and concepts of traditional residential environment construction in Huizhou ancient villages represented by Chengkan village, so as to make a beneficial discussion on the regional rural revitalization, the protection and development of traditional village human settlement environment.
\end{abstract}

\section{Introduction}

China is a country with an ancient civilization mainly based on the agglomeration space pattern of villages, village water system, street space environment, building environment and Shuikou landscape environment. Under the special historical conditions of nature, culture and social system, China has formed its unique concept of human settlement environment ${ }^{[1]}$. Human settlement environment refers to the place where human beings live together, which is the surface space closely related to human survival activities, as a general term of natural environment, living environment and social and cultural environment. In a broad sense, human settlement environment is composed of natural environment, artificial environment, social and economic environment and cultural environment. In a narrow sense, human settlement environment only refers to people's living and living place is also a space for social activities integrating with nature ${ }^{[2]}$

Due to the influence of nature, society and history, the living environment of Huizhou is different from other regions ${ }^{[3]}$. Chengkan village is an important historical and cultural heritage of Huizhou ancient village. The main feature of its location and layout is the high integration with the natural environment. It skillfully inherits the traditional Chinese cultural thought of "unity of man and nature", forming the traditional village living environment of "backing mountain, surrounding water and facing screen".

\section{Natural environment and historical and cultural background of Chengkan Village}

\subsection{Natural environment of ancient villages}

Chengkan village is located in Chengkan Town, Huizhou District, Huangshan City, Anhui Province. It is surrounded by mountains on all sides, with Longshan and Changchun mountains in the north, Lingjin mountain in the east, Ge mountain in the west and xiajie mountain in the south. Its altitude is $180-350$ meters, which makes the whole environment form the situation of "left green dragon, right white tiger, front rosefinch, and rear Xuanwu".

Chengkan village is located in a valley basin of about 80 hectares. Zongchuan river runs through the village from north to south, with a total length of about 19 kilometers and a drainage area of about 46 square kilometers. It is a tertiary tributary of Xin'an River, the main river in Huizhou. Zongchuan River enters Chengkan basin from Longshan mountain to Changchun mountain, flowing into fengle River in the south, and

\footnotetext{
* Corresponding author: cpaiwy@hsu.edu.cn
} 
then injecting Lianjiang River, a tributary of Xin'an River in the East. In addition to the Zongchuan River, there are streams in the Chengkan area: Shikeng and huanlikeng in the north, dongshankeng and shibukeng in the southeast, Yaokeng and pengkeng in the West (Fig.1).

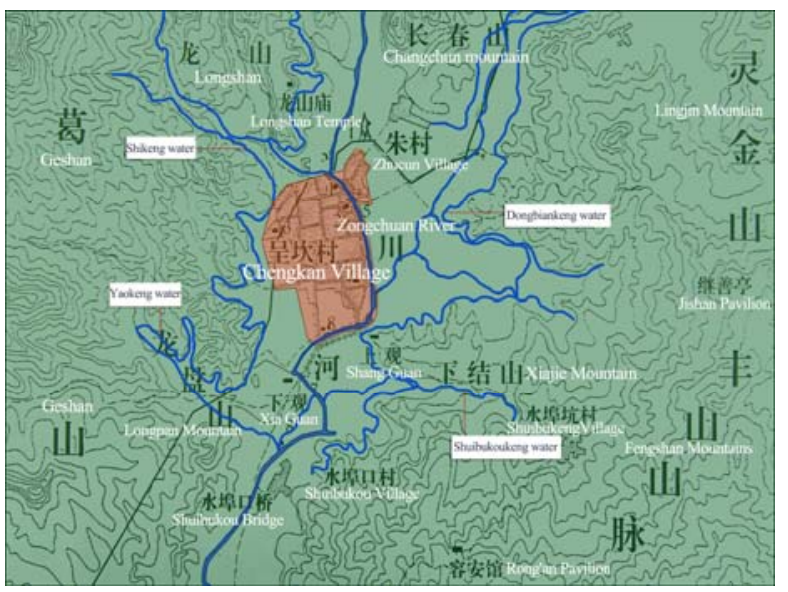

Fig. 1. Geographical environment and water system istribution map of Chengkan Village.

\subsection{Historical and cultural background of ancient villages}

The written history of Chengkan ancient village can be traced back to the end of the former Tang Dynasty, more than 1100 years ago. In order to avoid war and engage in business, Duke Luo qiuyin and his cousin Wenchang came to the place called Longxi at that time in order to avoid war and do business. According to historical records, the Luo brothers were familiar with Fengshui theory. They found that this place is surrounded by mountains on all sides and depressions in the middle. It is a typical place where "four rivers are contained in the village, and water is gathered as wealth". Therefore, they chose to live here.

Chengkan flourished in the song, yuan and Ming Dynasties. According to the genealogy of the Luo family in the Ming Dynasty, more than 110 people held official posts in the government. Among them, Luo Ruji, the Minister of bureaucrat in Song Dynasty, was more famous, and he was the chief judge of Yue Fei's unjust case. With the rise of Huizhou merchants, Luo's merchants spread all over the country. These officials and merchants returned to their hometown, built houses, ancestral temples and communities, which made Chengkan Village prosperous for a time.

\subsection{Cultural environment of ancient villages formed under natural environment and cultural background}

The geographical environment of "backing mountain, surrounding water and facing screen" and the development history of ancient villages spanning more than 1000 years have accumulated profound cultural heritages of Chengkan village(Fig.2). The development of Huizhou business economy has promoted the development of literature, art and architectural culture of Chengkan village, leaving a precious historical and cultural heritage for today's village.

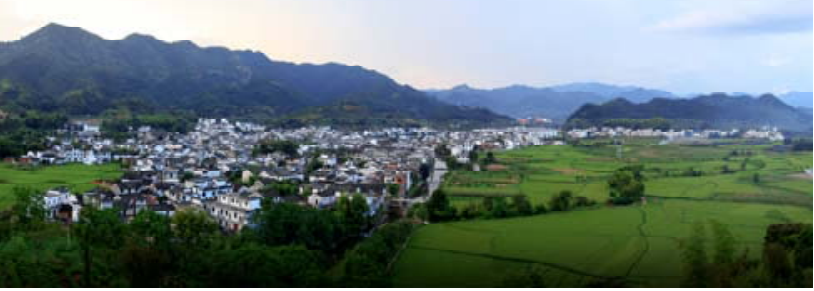

Fig. 2. Composition of living environment in Chengkan Village.

Chengkan village is now a famous historical and cultural village in China. There are more than 130 cultural relics and historical buildings in different periods of Ming and Qing Dynasties, such as ancient ancestral halls, ancient dwellings, ancient community houses, ancient watchtowers, ancient pavilions, ancient wells, and ancient bridges. Chengkan ancient village has two national key cultural relics protection units: luodongshu temple and Chengkan village ancient building complex, including three ancestral halls, one community house, one school, two shops, three watchtowers, two ancient bridges, two ancient wells, one gate tower and thirty-four residences, with a total of 49 .

Chengkan village is one of the most concentrated, preserved and characteristic ancient villages in southern Anhui Province. It contains a lot of historical information about the evolution and development of Huizhou traditional architecture from Ming Dynasty to Tsing Dynasty. It still retains some practices of song and Yuan Dynasties from the existing architectural remains of Ming Dynasty. It is a research on the historical evolution, structure and technology of Huizhou architecture. The scientific and technological development of Huizhou regional architecture in Ming and Tsing Dynasties is reflected from planning, site selection, environmental concept, spatial pattern, architectural form, architectural structure system, architectural modeling, etc.

\section{The main modes to create the living environment in Chengkan village}

\subsection{Build living settlement of harmony between man and nature in the village}

In the special geographical location and natural environment, people usually skillfully use the characteristics of this terrain to create a unique settlement pattern $^{[4]}$. The traditional culture of Huizhou, which takes Chengzhu jurisprudence as the spiritual core, is closely combined with the unique geographical environment of Huizhou region, which has direct guidance and influence on the location, layout and construction of ancient village road.

Based on the traditional geomantic theory, Chengkan ancient village adjusts the village spatial form in the process of village site selection, construction and development, so as to achieve the perfect combination of spiritual pursuit and human settlement environment 
construction. The change of the original Zongchuan river channel in the ancient village is a typical example of the adjustment of village spatial form.

The existing Zongchuan river channel in Chengkan Village was reconstructed on a large scale in Hongzhi period of Ming Dynasty (1488-1506). After the diversion, the Zongchuan river is zigzag. In terms of village construction and development, the change of river course has two meanings ${ }^{[5]}$ (Fig.3).

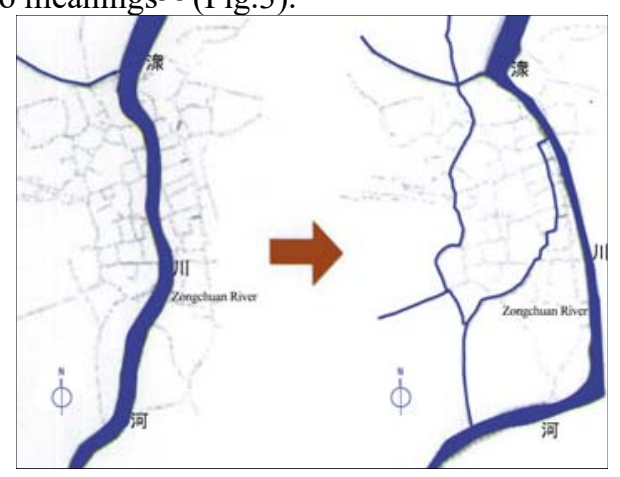

Fig. 3. Chengkan Village Zongchuan river channel change map (left: before change, right: after change).

On the one hand, with the rapid growth of the village population, the village construction also develops rapidly, and the Zongchuan river in the middle of the village hinders the development and construction of the village. The change of the river channel increases the ideal construction land of the village -- the land space on the west side of the Zongchuan river. On the other hand, it is close to the ideal geomantic state. The Chengkan Village before the river channel change met the Fengshui pattern of "back mountain and face screen" in ancient Huizhou area, but only "water ring" was not satisfing. Therefore, the change of "zigzag" river not only expanded the village construction land, but also formed the ideal geomantic pattern of "backing mountain, facing screen and surrounding water".

\subsection{Build a benign development of the village water system by adapting to the terrain}

Chengkan ancient village has a complete water conservancy system of "front River, middle ditch and back ditch"[6] (Fig.4). The "front River" refers to the Zongchuan river, which turns from the north to the southeast of the village, and then runs to the south, forming a good landscape of Shuikou Garden in the south of the village.

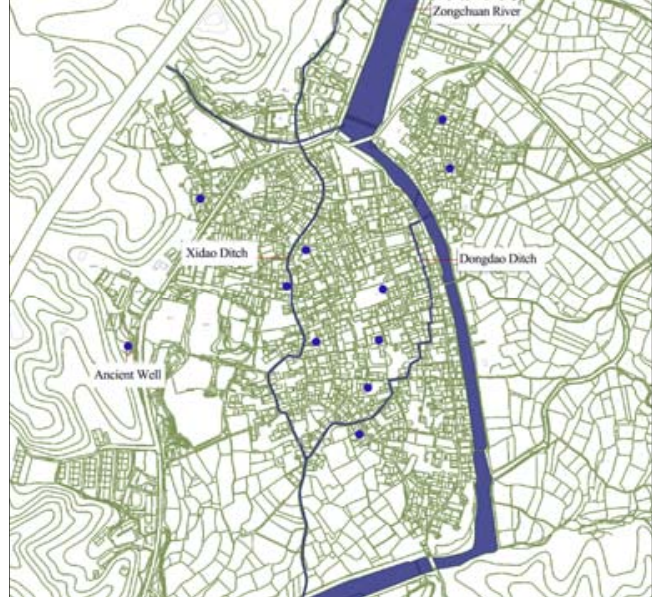

Fig. 4. Distribution of water system in Chengkan Village.

In order to solve the discharge of villagers' living, fire fighting, irrigation water and domestic sewage, two water channels were excavated manually: the "middle channel" in the East and the "back ditch" in the back street. The two will gather as the first-class in the south of the village. "Middle channel" is also called the east channel, which leads the river of Zongchuan River to Yongshun, Houluo general temple, Zhici, Luohuizheng mansion and Luohuitai mansion, through Shuizhen lane to the south of the village, and into the canal of the river. "Back ditch" means the small channel which leads to the west side of the village along the back street, and then flows into the middle channel.

In the 99th lane of the fifth street of Chengkan village, almost all households have water flowing in front of their doors (Fig.5), which shows that the water diversion and drainage facilities are not only reasonable, but also integrate the beauty of space form and environment. At the same time, the construction of this kind of facilities is not a single function consideration, but also a concept embodiment full of traditional cultural connotation. "Gathering water is like gathering money, taking four water in the village", the continuous flow of water expresses the long history and prosperous financial resources.

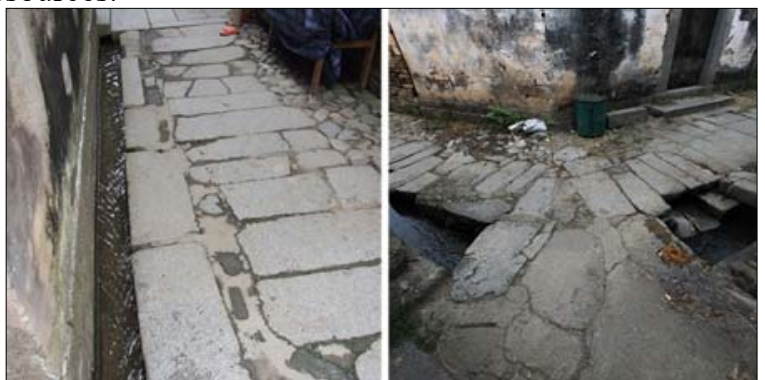

Fig. 5. Drainage system of Chengkan Village.

The water conservancy system of "Front river, middle ditch and back ditch" in Chengkan village and the unique street and lane pattern of "five streets and ninety-nine lanes" were formed by the ancients' careful planning and design based on a series of geomantic theories such as "pillow mountain, ring water, face screen", etc. ancient people in Huizhou not only respected nature and environment, but also successfully transformed nature 
and business Creating the environment, maintaining and expanding a balanced ecological environment.

\subsection{Rich and varied street space environment}

The main vein of the village extends along the Zongchuan River, which divides the village boundary into two parts: the East and the West. The two roads, called Daba and Xiaoba, enter the village along the river. The two roads meet at the head of Longxing bridge and are divided into front street and back street. These two streets are called "five streets" (Table 1), together with Zhongying street, Zhonger street and Xidong street in Hedong parallel. Vertical to the Zongchuan river, it is mostly alleys, known as ninety-nine lanes. Most of the streets and alleys in the village are very zigzag and changeable, ranging from less than 1 meter in width to about 3 meters in width(Fig.6).

Table 1. List of main streets and alleys in Chengkan Village.

\begin{tabular}{|c|c|c|}
\hline Street Name & Length (m) & Width (m) \\
\hline Xidong Street & 231 & 2.0 \\
\hline Front Street & 300 & $1.5-3.0$ \\
\hline Zhong Ying Street & 191 & $1.5-2.5$ \\
\hline Zhong Er Street & 127 & $1.5-2.0$ \\
\hline Back Street & 294 & 3.0 \\
\hline
\end{tabular}
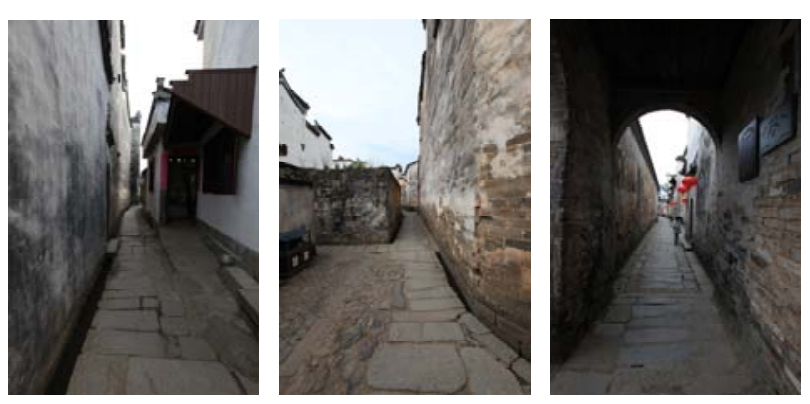

Fig. 6. The street space of Chengkan Village (from left to right is Xidong Street, Front Street, Zhong Ying Street)

\subsection{Create a unique architectural space environment with Huizhou characteristics by terrain features}

The design wisdom of living environment in Chengkan Village is also reflected in the construction of building space according to the terrain, mainly reflected in the building plane space and facade space.

The building characteristics of the plane layout in Chengkan village are mainly reflected in the natural layout. With the help of natural forms of mountains and rivers, there is no emphasis on certain geometric forms, let alone fixed patterns. The main house pursues the central axis as much as possible, but its wing rooms and other attached houses are flexible and changeable in the plane layout. The houses can be connected vertically and horizontally, and the deep courtyard is vertically and horizontally combined. The appearance is not required to be regular and symmetrical (Fig.7).

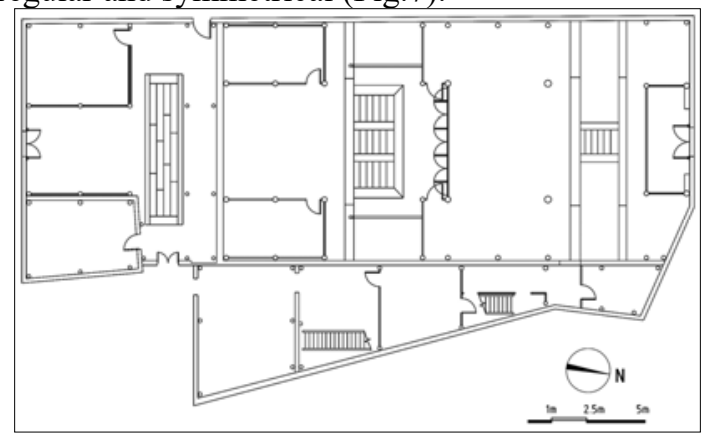

Fig. 7. Plan of Shangwu, Chengkan ancient village.

The ancient buildings in Chengkan village also show great flexibility in three-dimensional space. Because the number of main rooms and auxiliary buildings varies, the height of each house is different. At the same time, combined with the topography and topography of high / low changes, the mountain walls with different heights are formed. The whole ancient village has formed a rich and colorful group space image.

\subsection{Keeping Shuikou, as a pioneer in Chinese public garden landscape construction}

Shuikou is an indispensable and important part of the spatial form of Huizhou ancient villages, which forms Shuikou garden with regional cultural characteristics and humanistic spirit, and is a typical representative form of Huizhou regional traditional garden landscape. The appearance of Shuikou garden made up for the blank of Chinese ancient private garden, royal garden and temple garden, but no public garden.

In Huizhou ancient villages, combined with the natural relationship between the water system and the villages flowing through, water outlets are generally arranged at the head and end of the village. The combination of artificial construction and natural landscape of the water outlet not only respects and utilizes the natural form, but also creates artificially.

The Shuikou construction in Chengkan ancient village can also be divided into upper and lower water outlets. In the northern part of the village, Luodongshu Ancestral Hall is the Shuikou, also known as "Tianmen". According to local historical records, there are buildings such as Longshan Temple in the Shuikou area, surrounded by natural forest, which has basically no trace today. The Shuikou in longxingqiao, the southern head of the village, is also known as "Dihu". According to the theory of geomancy, it is an important part of storing wind and gathering gas. It is reported that there were upper and lower view gardens and upper and lower gardens in this area. Among them, there are Longxing bridge, Longxing Temple, Dutian temple, Guanyin temple and Baibu ladder in Shangguan, while those in Xiaguan include emperor temple, Wenhui hall, Wenchang Pavilion, Leji 
bridge, Kuang ruting and stone archway (Fig.8). Between the upper and lower views are the dam and the small dam, which makes the Zongchuan River turn westward from north to South at the foot of the mountain, and then to the South after the Longpan mountain, which makes the water flow at the water outlet bend, which is more in line with the traditional geomantic theory. Today's Xiashuikou, Longxing bridge is still towering on the Zongchuan river (Fig. 9,10), and you can feel the rich natural and cultural environment of Shuikou.

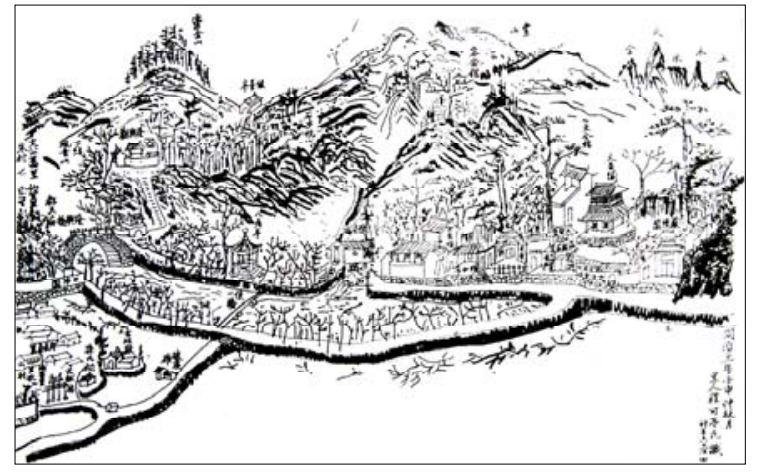

Fig. 8. Historical map of nanshuikou, Chengkan Village.

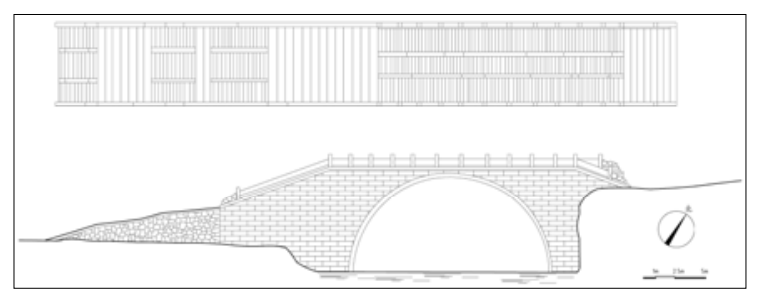

Fig. 9. Surveying and mapping drawings of Longxing bridge (top is plan and the bottom is elevation of Longxing bridge)
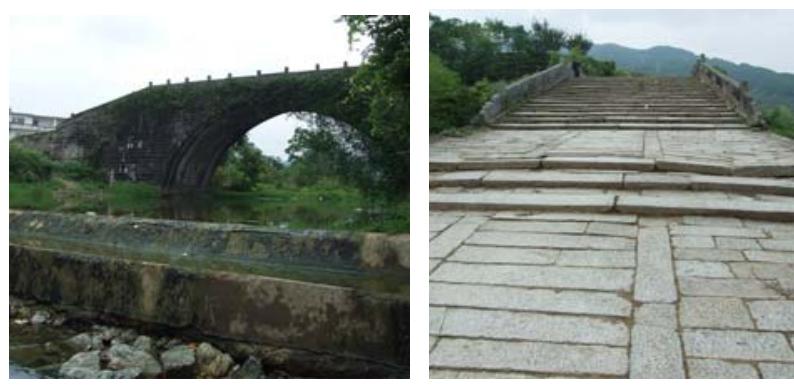

Fig. 10. Longxing bridge Conservation status in the south of Chengkan village

\section{Conclusion}

The geomantic environment surrounded by mountains and water reflects the scientific nature of ancient Huizhou ancestors in the selection of residential environment and the comprehensive application of simple traditional geomantic theory. With the development of science and the continuous improvement of human requirements for the quality of living environment, the construction of human settlement environment has gradually developed into an independent discipline, which has been widely concerned by professionals and ordinary people. Our ancestors have studied and practiced the construction of human settlement environment thousands of years ago.
Chengkan village, as one of the typical representatives of ancient villages in Huizhou, not only has the general spatial pattern of human settlements in Huizhou traditional villages, such as "back mountain, surrounding water and screen", but also has the typical characteristics of its unique culture, nature, architecture and so on. It provides an important example for our research, discussion and practice of human settlement environment Through the discussion and research of Huizhou ancient village human settlement environment, it is helpful for us to further understand and understand the construction concept of ancient human settlement environment, so as to provide practical research ideas and research methods for Rural Revitalization under the background of cultural self-confidence, initially solve the problem of "what to learn", and protect the traditional human settlement environment in Rural Revitalization Protection and inheritance need further discussion and practice, and then solve the problem of "how to learn", which is the main purpose and important practical goal of traditional human settlements.

\section{Acknowledgements}

This paper has been supported by the following fund projects. MOE (Ministry of Education of the People's Republic of China) Youth Fund Project of Humanities and Social Sciences (Project No.18YJC850002). Bidding Project of Key Research Base of Humanities and Social Sciences in Colleges and Universities of Anhui Province (Project No. SK2015A170). Special Funding Project of Innovatively Provincial Construction in Anhui Province (Project No.2020XZX001) . "10303 plan of Huizhou research talents training" project of Huangshan Social Science Federation. Natural Science Research Project of Anhui Education Department(Project No.KJHS2016B13). Anhui Education of Department Humanity and Social Science Research Project (Project No. SK2020A0468). National Innovation and Entrepreneurship Training Program for College Students(Project No. 201910375007X).

Thanks to Mr. Luo huiding of Chengkan Village and my tutor Professor Liu Boshan of Anhui University for their help, Anhui Huizhou Cultural Relics Engineering Survey and Design Co., Ltd. and Huangshan Social Science Federation for their support. At the same time, I would also like to thank other literature authors who have provided important references but failed to mark them one by one.

\section{References}

1. Wang Shusheng. Study on the construction of human settlements in historical cities along the Yellow River, Shanxi and Shanxi. Beijing: China Construction Industry Press, 2009

2. Wu Liangyong. Introduction to human settlements. Beijing: China Construction Industry Press, 2003 
3. Hu Minxian. Spatial study on human settlements in Huizhou ancient villages. Beijing Forestry University, 2007

4. Gao Qian. Analysis of human settlements in Shijiagou ancient village. Journal of Xi'an University of science and technology, 2013,33 (4): 490-493

5. Ni Qi, Wang Yu, et al. Spatial composition principle of traditional villages with water system as the core in Huizhou area of China: investigation report of Chengkan Village in Huizhou area of Huangshan City. Urban architecture, 2008 (11): 107-108

6. Bi Zhongsong, Li Yunzhang, et al. Protection object composition and protection strategy of "ancient village architectural complex" cultural relics. Architecture and culture, 2015 (06): 200-204 